\title{
Erratum to: Pediculicidal treatment using ethanol and Melia azedarach $\mathrm{L}$
}

\author{
João Ricardo Rutkauskis ${ }^{1}$. Debora Jacomini ${ }^{1}$ - Livia Godinho Temponi ${ }^{2}$. \\ Maria Helena Sarragiotto ${ }^{3}$. Edson Antonio Alves da Silva ${ }^{4}$. \\ Tereza Cristina Marinho Jorge ${ }^{1,5}$
}

Published online: 2 April 2015

(C) Springer-Verlag Berlin Heidelberg 2015

\section{Erratum to: Parasitol Res}

DOI 10.1007/s00436-015-4394-2

The original version of this manuscript contained a mistake in the author name. The correct author name should be 'Tereza Cristina Marinho Jorge' and not 'Tereza Cristina Marino Jorge'.

The online version of the original article can be found at http://dx.doi.org/ 10.1007/s00436-015-4394-2.

Tereza Cristina Marinho Jorge

Tereza.Jorge@unioeste.br

1 Center of Medical Sciences and Pharmaceutical, UNIOESTE,

Cascavel, Brazil

2 Center of Biological and Health Sciences, UNIOESTE,

Cascavel, Brazil

3 Center of Exact Sciences, Department of Chemistry, Universidade Estadual de Maringá (UEM), Colombo Av. no. 5790, Maringá, PR, Brazil

4 Center of Exact Sciences and Technology, UNIOESTE, Cascavel, Brazil

5 Laboratory of Pharmacognosy, Universidade Estadual do Oeste do Paraná (UNIOESTE), University Street no. 2069, University Campus, 85819-110 Cascavel, PR, Brazil 